Original scientific paper Submitted: 2020-06-13

Published: 2020-08-31

doi:10.5937/nabepo25-27062

\title{
ACCURACY OF BODY MASS INDEX BASED ON SELF-REPORT DATA AMONG LAW ENFORCEMENT CADETS
}

\author{
${ }^{1}$ Quincy R. Johnson, ${ }^{2}$ Jillian M. Joyce, ${ }^{3}$ Filip Kukić ${ }^{1},{ }^{4}$ Robert G. Lockie \\ ${ }^{5}$ Charles L. Kornhauser, ${ }^{6}$ Robin M. Orr, ${ }^{1}$ J. Jay Dawes \\ ${ }^{1}$ Oklahoma State University, School of Kinesiology, Applied Health \\ and Recreation Stillwater, OK, USA \\ ${ }^{2}$ Oklahoma State University, Department of Nutritional Sciences \\ Stillwater, OK, USA \\ ${ }^{3}$ Abu Dhabi Police, Police Sports Education Center, United Arab Emirates \\ ${ }^{4}$ California State University, Department of Kinesiology \\ Fullerton, CA, USA \\ ${ }^{5}$ Colorado State Patrol Department Headquarters, Golden, CO, USA \\ ${ }^{6}$ Bond University, Tactical Research Unit, Robina, Qld, Australia
}

\begin{abstract}
BACKGROUND - Height and body mass are often self-reported by study participants. However, the accuracy of this data compared to measured values is limited in tactical trainee populations. This study's purpose was to compare the accuracy of self-reported height and body mass to measured values within a US law enforcement cadet population, and determine how these estimations affected BMI classifications. METHODS - Self-reported and measured body height and body mass for twenty-six $(n=26)$ male and female cadets (males - age: $31.32 \pm 10.04$ years; measured height: $178.07 \pm 9.87 \mathrm{~cm}$; measured body mass: $92.44 \pm 19.37 \mathrm{~kg}$; females - age: $25.67 \pm 1.53$ years; measured body height: $168.17 \pm 4.01 \mathrm{~cm}$; measured body mass: $78.94 \pm 11.30 \mathrm{~kg}$ ) were analyzed. RESULTS - Significant differences between estimated and measured height $(\mathrm{p}<0.001)$, body mass $(\mathrm{p}<0.05)$, but not BMI $(\mathrm{p}=0.281)$ were revealed. CONCLUSION - Self-reported body height and body mass were not accurately reported when compared to measured values. However, reported resulted in accurate BMI classifications.
\end{abstract}

Keywords: anthropometrics, health assessment, police, obesity.

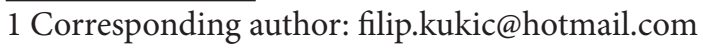




\section{INTRODUCTION}

The physical demands of law enforcement officers (LEOs) range from sedentary (i.e. administrative work) to strenuous (i.e., those such as pursuit, body drag, stair climbing or arresting uncooperative suspects) (Dawes et al., 2018). In that regard, occupational health and physical performance of LEOs are very important components for safe, effective, and efficient job performance (Dawes et al., 2018; Dawes et al., 2016; Kukić et al., 2018; Steinhardt et al., 1991). For this reason, physical fitness of LEOs is typically a mandatory part of police training and in some law enforcement agencies it is used as a tool for selection of candidates (Koropanovski et al., 2020; Lagestad \& Van Den Tillaar, 2014; Lockie et al., 2019; Dawes et al., 2019b). Physical fitness could be defined as health-related and performance-related, whereby anthropometrics and body composition play an important role (Dawes et al., 2018; Kukić et al., 2018; Kukić et al., 2020; Kukić \& Čvorović, 2019; Riebe et al., 2018). However, the assessment of anthropometrics and body composition is not always feasible due to limited equipment, trained personnel, and/or time. Considering the extent to which increased body mass (BM) relative to body height $(\mathrm{BH})$ can negatively affect the health (Garbarino \& Magnavita, 2015; Violanti et al., 2017) and physical performance (Dawes et al., 2018; Dawes et al., 2016) of LEOs, accurate yet feasible methods for evaluation of anthropometric status should be identified for the LEO population.

Body mass index (BMI) has been extensively utilized in public and occupational health (Bhaskaran et al., 2018; Ćopić et al., 2020; Ernsberger, 2012; Kukić et al., 2020) as it only requires a person's
$\mathrm{BM}$ and $\mathrm{BH}$ for the calculation (Eknoyan \& Adolphe, 2008; Čvorović et al., 2018). This is of importance given that people of different sizes may differ in BM merely because they are taller, rather than having greater amounts of body fat. Longitudinal body dimensions, such as $\mathrm{BH}$, follow a particular specific pattern during growth (Kirchengast, 2010), while components of the body that constitute the body volume, such as skeletal and fat tissue, could be altered by physical activity, hypokinesia, nutrition, education, and socioeconomic constructs of society (Dinsa et al., 2012; Kukić et al., 2020; Kukić \& Čvorović, 2019; Vuković et al., 2020). Therefore, changes in body composition of adults (i.e., increase or decrease in body fat and/or skeletal muscle mass) often reflect in changes in $\mathrm{BM}$, leading to changes in BMI.

Although BMI does not provide specific information on the source of either body volume or size (Provencher et al., 2018; Rothman, 2008), the validity of its utilization relies on consistent associations with biological and socioeconomic factors, such as age, sex, education, occupation, and income (Ball et al., 2002; Boyce et al., 2008; Kukić et al., 2019; Sobal, 1991; Sörensen et al., 2000). In that regard, the World Health Organization and American College of Sports Medicine often times use the standard values of BMI for the evaluation of health status (Riebe et al., 2018; WHO, 2017). These values are easily attainable and are cost-effective, which is of high importance for law enforcement agencies that need to assess large groups of people in a short time. Therefore, multiple studies on LEOs utilized BMI to evaluate obesity rates in LEO populations (Alghamdi et al., 2017; Dopsaj \& Vuković, 2015; 
Kukić \& Dopsaj, 2016). Accurate self-report BMI could provide important information about an officer as it provides insights into body status, and indirectly, physical fitness and health (Bhaskaran et al., 2018; Riebe et al., 2018; WHO, 2017). Noting this need for accurate reporting and associated time constraints in a LEO population, research by Dawes et al. (2019a) reported the acceptable accuracy of self-report BMI within a sample of police officers.

Considering that cadets are to become LEOs, their ability to accurately self-report $\mathrm{BM}$ and $\mathrm{BH}$, thereby BMI could establish standardized procedures for obtaining this information. Moreover, these measures could provide insight into their self-awareness about their body status, which is important if their body status needs improvements. However, acknowledging the work by Dawes et al. (2019a), the accuracy of self-reported measures in law enforcement cadet populations has not yet been established. In that regard, the aim of this study was to evaluate the accuracy of BMI calculated from self-reported $\mathrm{BM}$ and $\mathrm{BH}$ among a cohort of law enforcement cadet. The researchers hypothesize that self-reported $\mathrm{BH}$ and BM data would not be significantly different from measured values and that accurate reporting would lead to accurate BMI classifications.

\section{METHODS}

\section{Experimental approach to the problem}

Self-reported and measured $\mathrm{BH}$ and BM data were collected from law enforcement cadets belonging to a US law enforcement agency upon entrance into their respective police academy. This data were then provided to the primary investigator for analysis and comparison.

\section{Subjects}

Self-reported and measured $\mathrm{BH}$ and $\mathrm{BM}$ data for twenty-six $(\mathrm{n}=26$; males $=$ 23 , females $=3$ ) law enforcement cadets (males - age $=31.32 \pm 10.04$ years; females - age $=25.67 \pm 1.53$ years) from one US based law enforcement agency located in the Rocky Mountain Region were collected and utilized for this analysis. Prior to data collection, law enforcement cadets were informed of the study's purpose and were asked to provide informed consent allowing investigators to utilize their self-reported $\mathrm{BH}$ and BM data, as well as allowing members of the training staff to measure their actual $\mathrm{BH}$ and BM. Ethical approval to analyze this information was obtained from the Oklahoma State University Institutional Review Board (IRB 16-041) for human subjects. 


\section{Procedures}

All self-reported and measured $\mathrm{BH}$ and BM measurements were collected indoors at the law enforcement training facility. Additionally, all data were collected in the morning before training began on the first and second day of training academy. The protocols for collection of these measurements are detailed hereafter.

Self-reported age, $B H$ and BM: Age (years), BH (in), and BM (lbs) values were self-reported by the cadets on a standard data sheet provided to each of them by the training staff in the morning, prior to training. All imperial measures, such as inches (in) and pounds (lbs), were converted to metric values for analysis.
Measured $B H$ and $B M: B H(\mathrm{~cm})$ and BM (kg) were measured shoeless, using a portable stadiometer (Seca ${ }^{\varpi} 222$, California, USA) and a digital electronic scale (Health-O-Meter ${ }^{\oplus}$, McCook, IL, USA) following procedures previously reported by Dawes et al. (2019a).

Body mass index (BMI) calculation and classification: BMI was calculated during analysis after converting the measurements of $\mathrm{BH}$ and $\mathrm{BM}$ into the appropriate metric units. BMI was derived using the equation $\mathrm{BMI}=$ body mass $(\mathrm{kg}) /$ [height $(\mathrm{m})]^{2}$. Once calculated, National Institute of Health (1998) BMI classification ranges were used to group officers by weight status (Table 1 ).

Table 1. Body Mass Index (BMI) classification according to the National Institutes of Health, 1998

\begin{tabular}{|c|c|}
\hline Weight Status & BMI Values \\
\hline Underweight & $<18.5 \mathrm{~kg} / \mathrm{m}^{2}$ \\
\hline Normal & $18.5-24.9 \mathrm{~kg} / \mathrm{m}^{2}$ \\
\hline Overweight & $25.0-29.9 \mathrm{~kg} / \mathrm{m}^{2}$ \\
\hline Obesity I & $30.0-34.9 \mathrm{~kg} / \mathrm{m}^{2}$ \\
\hline Obesity II & $35.0-39.9 \mathrm{~kg} / \mathrm{m}^{2}$ \\
\hline Obesity III - Extreme obesity & $>40.0 \mathrm{~kg} / \mathrm{m}^{2}$ \\
\hline
\end{tabular}

\section{Statistical analysis}

Collected data were entered into a computer file suitable for statistical analysis using the Statistics Package for Social Sciences (SPSS) (Version 25.0; IBM Corporation, New York, USA). A descriptive statistical analysis was conducted to determine the mean values and standard deviations for the total sample and on all collected data. Comparisons between self-reported and measured values for each of the variables were conducted using a series of paired samples t-tests with alpha levels set at 0.05 a priori. Cohen's effect sizes $(d)$ were calculated as the ratio of the difference in mean scores to standard deviation, following the formula: $d=\left(\mathrm{M}_{2}-\mathrm{M}_{1}\right) / \mathrm{SD}$, where $M_{1}$ and $M_{2}$ were the means of the groups investigated and the SD was a pooled standard deviation of compared groups. The magnitude of the effects was defined as follows: small $=0.2$, moderate $=0.6$, large $=1.2$ and very large $=2.0$ (Sullivan \& Feinn, 2012) 


\section{Results}

The descriptive data and comparisons between estimated and measured anthropometrics for this sample are presented in Table II. The results of the paired samples t-tests revealed significant differences in both, estimated and measured $\mathrm{BH}(\mathrm{t}(24)$ $=-4.34, \mathrm{p}<0.001)$, and estimated and measured $\mathrm{BM}(\mathrm{t}(24)=-2.575, \mathrm{p}=0.017)$, whereby the differences were trivial size (Figure 1). However, in this study, the self-reported data had $100 \%$ of law enforcement cadets classified into the same $\mathrm{Na}$ tional Institute of Health's BMI classification scale as the categories determined using the objective measures. There were no significant differences revealed between estimated and measured BMI $(\mathrm{t}(24)=1.104, \mathrm{p}=0.281)$. Further, when separately evaluating BMI data based on measured $\mathrm{BH}$ and $\mathrm{BM}$, it was found that one cadet in this study was "underweight", four were "normal weight", eight were "overweight", 10 were classified as "obesity I", two were classified as "obesity II", and 0 were classified as "obesity III" (Figure 2).

Table 2. Descriptive data and comparisons

\begin{tabular}{|l|c|c|c|}
\hline Variable & $\begin{array}{c}\text { Self-Reported Mean } \\
\pm \text { SD (range) }\end{array}$ & $\begin{array}{c}\text { Measured Mean } \\
\pm \text { SD (range) }\end{array}$ & $\begin{array}{c}\text { Differences Mean } \\
\pm \text { SD (range) }\end{array}$ \\
\hline BH (cm) & $\begin{array}{c}178.36 \pm 10.34^{\star *} \\
(157.48-195.58)\end{array}$ & $\begin{array}{c}176.88 \pm 9.87 \\
(158.00-196.50)\end{array}$ & $\begin{array}{c}1.48 \pm 0.47 \mathrm{~cm} \\
(-0.08-0.52)\end{array}$ \\
\hline BM (kg) & $\begin{array}{c}91.87 \pm 19.52^{\star} \\
(61.36-143.18)\end{array}$ & $\begin{array}{c}90.82 \pm 18.95 \\
(59.90-139.73)\end{array}$ & $\begin{array}{c}1.05 \pm 0.57 \mathrm{~kg} \\
(1.46-3.45)\end{array}$ \\
\hline Estimated BMI & $\begin{array}{c}28.79 \pm 5.07 \\
(19.01-44.03)\end{array}$ & $\begin{array}{c}28.95 \pm 5.09 \\
(18.93-43.37)\end{array}$ & $\begin{array}{c}0.16 \pm 0.02 \\
(0.08-0.66)\end{array}$ \\
\hline
\end{tabular}

${ }^{*}$ Significant difference at $\mathrm{p} \leq 0.05 ;{ }^{*}$ Significant difference at $\mathrm{p} \leq 0.01$
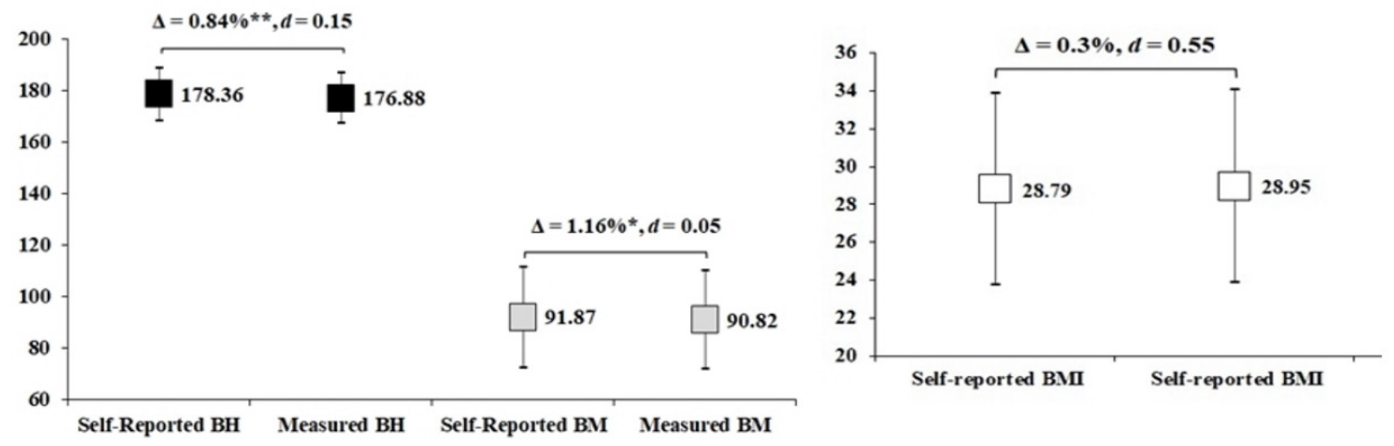

Figure 1. Relative differences $(\Delta[\%])$ and effect sizes $(d)$ between self-reported and measured anthropometric indices 


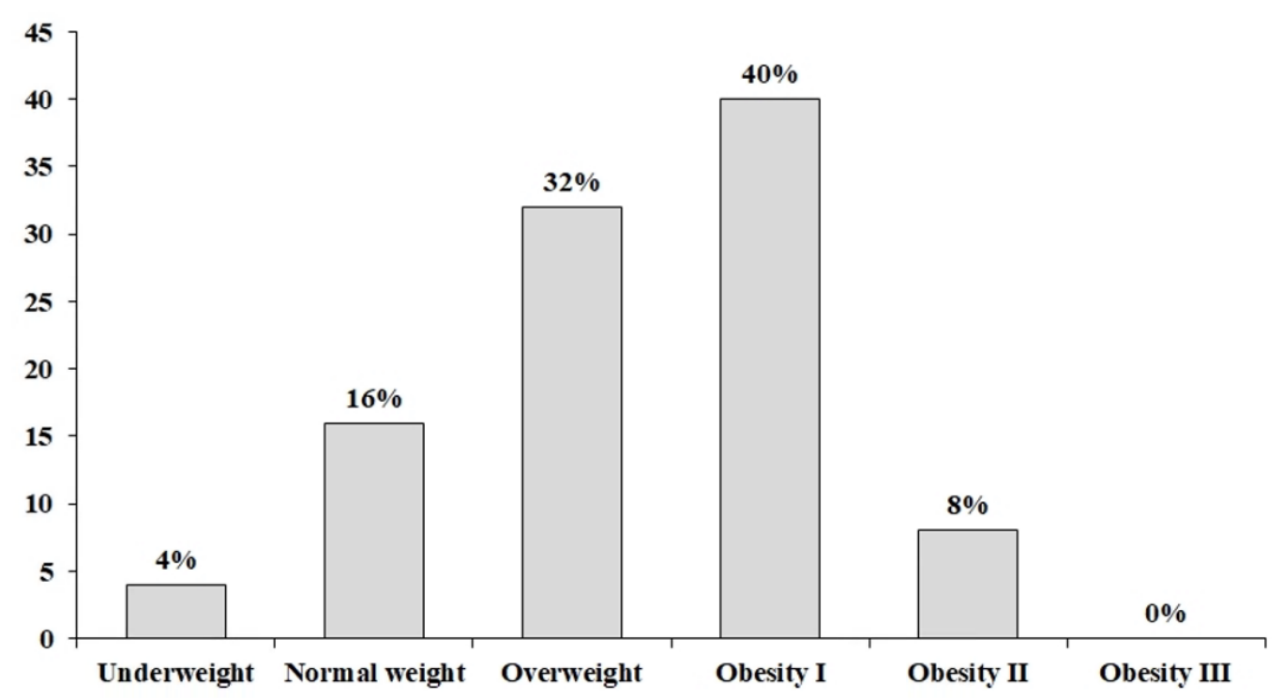

Figure 2. Prevalence of cadets according to BMI classification

\section{DISCUSSION}

The purpose of this investigation was to compare the accuracy of self-reported $\mathrm{BH}$ and $\mathrm{BM}$ data to measured values among a population of law enforcement cadets, and determine if correct BMI classifications could be determined using self-reported data. It was discovered that law enforcement cadets reported significantly greater $\mathrm{BH}$ and lower $\mathrm{BM}$ when compared to measured values. However, no significant differences were discovered when calculating BMI based on self-reported or measured data. Based on these results, it appears that self-reported $\mathrm{BH}$ and $\mathrm{BM}$ data, though less accurate, may allow for an accurate assessment of general weight status via BMI among law enforcement cadets. This is the first study to investigate the accuracy of self-reported anthropometric data in the law enforcement cadet population. Based on these findings the researchers rejected the hypothesis that self-reported $\mathrm{BH}$ and $\mathrm{BM}$ data would not be significantly different from measured values. However, the researchers rejected the hypothesis that no differences in this data would lead to accurate BMI classifications. It seems that the results from this study have implications for strength and conditioning coaches and training staff that are responsible for developing health and wellness interventions for law enforcement cadets, and for researchers and other health experts who, due to time constrictions or resource availability, often must rely on self-reported $\mathrm{BH}$ and BM measures in order to stratify law enforcement cadets into groups based on weight status. It may be concluded that self-reported anthropometric data can be used as an easy and cost-effective tool for accurately determining the BMI in this population, despite inaccuracies in self-reported $\mathrm{BH}$ and $\mathrm{BM}$.

Numerous studies have documented significant differences between measured and self-reported $\mathrm{BH}$ status, with the 
tendency to overestimate (greater than measured) being very common (Bowring et al., 2012; Nyholm et al., 2007; Wen \& Kowaleski-Jones, 2012; Martin et al., 2016). Additionally, differences have also been reported between sexes, where males generally overestimate $\mathrm{BH}$ and both sexes underestimated BM (Olfert et al., 2018). Several factors may be responsible for this occurrence including inadequate training regarding $\mathrm{BH}$ estimation, self-report bias, and desire to please. The results of this study are consistent with these findings. Self-reported $\mathrm{BH}$ significantly differed from measured $\mathrm{BH}$ by $0.8 \%( \pm 4.6)$ on average, where cadets overestimated self-reported values. However, these results are in contrast to those presented by Dawes et al. (2019a) who found no significant differences between self-reported and measured $\mathrm{BH}$ among LEOs. The results of the current study suggest that cadets tend to be less accurate than LEOs and similar to the general population when providing self-report $\mathrm{BH}$ data (Dawes et al., 2019a; Maukonen et al., 2018; Olfert et al., 2018; Bowring et al., 2012; Nyholm et al., 2007; Wen \& Kowaleski-Jones, 2012; Martin et al., 2016). In fact, four law enforcement cadets underreported their $\mathrm{BH}, 17$ over-reported their $\mathrm{BH}$, and four law enforcement cadets were exact in their estimations. However, none of these estimations resulted in a misclassification of BMI for the cadets in this study. For that reason, self-reported $\mathrm{BH}$ and $\mathrm{BM}$ values can be utilized to accurately calculate $\mathrm{BMI}$ in the instance that there are limited resources and/or time to conduct measurements.

Previous investigations have illustrated inaccuracies between self-reported and measured BM among general populations (Maukonen et al., 2018; Olfert et al., 2018). Specifically, self-reported BM tends to be underestimated (lower than measured) (Bowring et al., 2012, Nyholm et al., 2007; Wen and Kowaleski-Jones, 2012; Martin et al., 2016). Similar to BH, inadequate training regarding BM estimation, self-report bias, and desire to please could contribute to inaccuracies in self-reporting BM. Among the sample of law enforcement cadets in this study, self-reported BM was significantly lower than measured BM by $1.2 \%( \pm 2.9)$ on average. It was discovered that six law enforcement cadets underreported their BM, 15 over-reported their BM, and four law enforcement cadets were exact in their measurement. However, none of these estimations resulted in a misclassification of BMI for the officers in this study. Thus, when used in conjunction with self-reported $\mathrm{BH}$, self-reported BM can serve as a reliable replacement for actual BM measurements if the goal is to calculate BMI and classify cadets based on their weight status.

Self-reported $\mathrm{BH}$ and $\mathrm{BM}$ data have been used in previous research to estimate BMI and overall weight status among both general and tactical populations (Bowring et al., 2012, Nyholm et al., 2007; Wen and Kowaleski-Jones, 2012; Martin et al., 2016). If misreported or misrepresented, this self-reported data can lead to inaccurate estimations and misclassifications of an individual's weight status. In this study, when using self-reported data, $100 \%$ of the law enforcement cadets were classified correctly according to the National Institute of Health's BMI classification scale and as classified by the measured values. Additionally, BMI from self-reported and measured $\mathrm{BH}$ and $\mathrm{BM}$ values only differed by $0.16 \mathrm{~kg} / \mathrm{m}^{2}( \pm 0.02)$ on average. Thus, it appears that within this population self-reported $\mathrm{BH}$ and $\mathrm{BM}$ could be used to accurately determine epidemio- 
logical information (i.e. general health risk or status) and as an alternative anthropometric measure if there are limited resources or access to assess such.

A notable limitation to this study is that it did not analyze the relationship between self-report bias and weight status. That is, assessing whether intentionally underestimating or overestimating $\mathrm{BH}$ and $\mathrm{BM}$ occurs for specific weight statuses. Previous research conducted by Maukonen et al. (2018) compared self-reported and measured anthropometrics in assessing obesity in adults. The investigators reported that there was a clear tendency for participants classified as overweight and obese to underestimate their BM. Additionally, this bias was much greater in overweight and obese participants than those of normal weight. Furthermore, a low power to detect differences in BMI based on sample size and group stratification, a smaller female sample compared to the male sample, and the accuracy of equipment used by participants and researchers could each be considered a potential limitation. Future studies may find it beneficial to investigate differences between self-reported $\mathrm{BH}$ and $\mathrm{BM}$ and measured $\mathrm{BH}$ and $\mathrm{BM}$ between law enforcement cadet groups stratified by weight status and sex (Maukonen et al., 2018).

\section{CONCLUSION}

The results of this study suggest that law enforcement cadets inaccurately self-reported both their $\mathrm{BH}$ and $\mathrm{BM}$ when compared to measured values. Several factors may be responsible for this occurrence including inadequate training regarding $\mathrm{BH}$ and $\mathrm{BM}$ estimation, self-report bias, and desire to please. However, based on the results of this study, when using a broad BMI classification scale, self-reported $\mathrm{BH}$ and $\mathrm{BM}$ can be used to accurately determine BMI classification groups. When the ability to objectively measure $\mathrm{BH}$ and $\mathrm{BM}$ for $\mathrm{BMI}$ determination is not viable for law enforcement staff, self-reported data can be used as a surrogate. However, if any of the data indicates a health risk (i.e. BMI $>25 \mathrm{~kg} /$ $\mathrm{m}^{2}$ ), or if $\mathrm{BH}$ and $\mathrm{BM}$ directly relate to occupational tasks, it is recommended that staff use more accurate and/or additional methods to directly measure $\mathrm{BH}$, BM, BMI, and adiposity.

\section{REFERENCES}

Alghamdi, A.S., Yahya, M.A., Alshammari, G.M. \& Osman, M.A. (2017). Prevalence of overweight and obesity among police officers in Riyadh City and risk factors for cardiovascular disease. Lipids in Health and Disease, 16, 79.

Ball, K., Mishra, G. \& Crawford, D. (2002). Which aspects of socioeconomic status are related to obesity among men and women? International Journal of Obesity, 26, 559-565. 
Bhaskaran, K., Dos-Santos-Silva, I., Leon, D.A, Douglas, I.J. \& Smeeth, L. (2018). Association of BMI with overall and cause-specific mortality: a population-based cohort study of 3.6 million adults in the UK. The Lancet Diabetes \& Endocrinology, 6, 944-953.

Bowring, A.L., Peeters, A., Freak-Poli, R., Lim, M.S., Gouillou, M. \& Hellard, M. (2012). Measuring the accuracy of self-reported height and weight in a community-based sample of young people. BMC Medical Research Methodology, 12, 175.

Boyce, R., Jones, G., Lloyd, C. \& Boone, E. (2008). A longitudinal observation of police: body composition changes over 12 years with gender and race comparisons. Journal of Exercise Physiology Online, 11(6), 1-13.

Ćopić, N., Kukić, F., Tomić, I., Parčina, I. \& Dopsaj, M. (2020). The impact of shift work on nutritional status of police officers. Journal of Criminalistics and Law, 25(1), $1-12$.

Čvorović, A., Kukić, F., Orr, R.M., Dawes, J.J., Jeknić, V. \& Stojković, M. (2018). Impact of a 12-week postgraduate training course on the body composition and physical abilities of police trainees. Journal of Strength and Conditioning Research, [published online ahead of print, 2018 Oct 17]

Čvorović, A., Orr, R., and Bacetić, N. (2018). Effects of a 12-week physical training program and nutrition plan on the body composition of overweight police trainees. In D. Simović (Ed.), International Scientific Conference "Archibald Reiss Days" (Vol. 2, pp. 49-59). Belgrade: Academy of Criminalistic and Police Studies.

Dawes, J.J., Kornhauser, C., Crespo, D., Elder, C.L., Lindsay, K. \& Holmes, R.J. (2018). Does body mass index influence the physiological and perceptual demands associated with defensive tactics training in state patrol officers? International Journal of Exercise Science, 11, 319.

Dawes, J.J., Lockie, R.G., Kukić, F., Čvorović, A., Kornhauser, C., Holmes, R. \& Orr, R.M. (2019). Accuracy of self-reported height, body mass and derived body mass index in a group of law enforcement officers. Journal of Criminalistics and Law, 24(2), 7-15.

Dawes, J.J., Lockie, R.G., Orr, R.M., Kornhauser, C. \& Holmes, R. (2019). Initial fitness testing scores as a predictor of police academy graduation. Journal of Australian Strength and Conditioning, 27, 30-37.

Dawes, J.J., Orr, R.M., Siekaniec, C.L., Vanderwoude, A.A. \& Pope, R. (2016). Associations between anthropometric characteristics and physical performance in male law enforcement officers: a retrospective cohort study. Annals of Occupational and Environmental Medicine, 28, 26.

Dinsa, G.D., Goryakin, Y., Fumagalli, E. \& Suhrcke, M. (2012). Obesity and socioeconomic status in developing countries: a systematic review. Obesity Reviews, 13, 1067-1079. 
Dopsaj, M. \& Vuković, M. (2015). Prevalence of the body mass index (BMI) among the members of the ministry of interior of the republic of Serbia: Pilot study. Bezbednost, Beograd 57, 28-48.

Eknoyan, G. (2008). Adolphe Quetelet (1796-1874) the average man and indices of obesity. Nephrology Dialysis Transplantation, 23(1), 47-47.

Ernsberger, P. (2012). BMI, body build, body fatness, and health risks. Fat Studies, $1(1), 6-12$.

Garbarino, S. \& Magnavita, N. (2015). Work stress and metabolic syndrome in police officers. A prospective study. PloS One, 10(12), 1-15.

Kirchengast, S. (2010). Gender differences in body composition from childhood to old age: An evolutionary point of view. Journal of Life Sciences, 2, 1-10.

Koropanovski, N., Kukić, F., Janković, R., Dimitrijević, R., Dawes, J.J., Lockie, R.G. \& Dopsaj, M. (2020). Impact of physical fitness on recruitment and its association to study outcomes of police students. South African Journal for Research in Sport, Physical Education and Recreation, 42(1), 23-34.

Kukić, F. \& Čvorović, A. (2019). The strategic approach to an improvement of health-related physical fitness of police officers: An 8-week exercise intervention: Pilot study. Bezbednost, Beograd, 61, 28-45.

Kukić, F. \& Dopsaj, M. (2016). Structural analysis of body composition status in Abu Dhabi police personnel. Journal of Criminalistics and Law, 21, 19-38.

Kukic, F., Cvorovic, A., Dawes, J.J. \& Koropanovski, N. (2017). Body mass index differences of police cadets and police employees. In S., Mandarić, L., Moskovljević, M., Marković, and M., Ćosić (Ed.), International Scientific Conference "Effects Of Applying Physical Activity On Anthropological Status Of Children, Adolescents And Adults" (pp. 193-198). Belgrade, Faculty of Sport and Physical Education, University of Belgrade.

Kukic, F., Dopsaj, M., Dawes, J.J., Orr, R. \& Cvorovic, A. (2018). Use of human body morphology as an indication of physical fitness: implications for police officers. International Journal of Morphology, 36, 1407-1412.

Kukić, F., Dopsaj, M., Nikić, M.Đ., Koropanovski, N., Maksimović, M., Eminović, F. \& Dopsaj, V. (2020). Educational status, leisure-time physical activity and body composition in Serbian adult population. Iranian Journal of Public Health, 49, 606-608.

Kukic, F., Koropanovski, N., Jankovic, R., Cvorovic, A., Dawes, J.J., Lockie, R.G., Orr, R.M. \& Dopsaj, M. (2020). Association of sex-related differences in body composition to change of direction speed in police officers while carrying load. International Journal of Morphology, 38, 731-736.

Kukic, F., Scekic, A., Koropanovski, N., Cvorovic, A., Dawes, J.J. \& Dopsaj, M. (2019). Age-related body composition differences in female police officers. International Journal of Morphology, 37(1), 302-307. 
Lagestad, P. \& Van den Tillaar, R. (2014). A comparison of training and physical performance of police students at the start and the end of three-year police education. Journal of Strength \& Conditioning Research, 28, 1394-1400.

Lockie, R.G., Balfany, K., Bloodgood, A.M., Moreno, M.R., Cesario, K.A., Dulla, J.M., Dawes, J.J. \& Orr, R.M.. (2019). The influence of physical fitness on reasons for academy separation in law enforcement recruits. International Journal of Environmental Research and Public Health, 16, 372.

Lockie, R.G., Dawes, J.J., Orr, R.M. \& Dulla, J.M. (2020). Recruit fitness standards from a large law enforcement agency: Between-class comparisons, percentile rankings, and implications for physical training. Journal of Strength \& Conditioning Research, 34, 934-941.

Martin, R.C., Grier, T., Canham-Chervak, M., Anderson, M.K., Bushman, T.T., DeGroot, D.W. \& Jones, B.H. (2016). Validity of self-reported physical fitness and body mass index in a military population. Journal of Strength \& Conditioning Research, 30, 26-32.

Maukonen, M., Männistö, S. \& Tolonen, H. (2018). A comparison of measured versus self-reported anthropometrics for assessing obesity in adults: a literature review. Scandinavian Journal of Public Health, 46, 565-579.

Nyholm, M., Gullberg, B., Merlo, J., Lundqvist-Persson, C., Råstam, L. \& Lindblad, U. (2007). The validity of obesity based on self-reported weight and height: implications for population studies. Obesity, 15, 197-208.

Olfert, M.D., Barr, M.L., Charlier, C.M., Famodu, O.A., Zhou, W., Mathews, A.E., Byrd-Bredbenner, C. \& Colby, S.E. (2018). Self-reported vs. measured height, weight, and BMI in young adults. International Journal of Environmental Research and Public Health, 15, 2216.

Provencher, M.T., Chahla, J., Sanchez, G., Cinque, M.E., Kennedy, N.I., Whalen, J., Price, M.D., Moatshe, G. \& LaPrade, R.F. (2018). Body mass index versus body fat percentage in prospective national football league athletes: overestimation of obesity rate in athletes at the national football league scouting combine. Journal of Strength \& Conditioning Research, 32, 1013-1019.

Riebe, D., Ehrman, J. K., Liguori, G., Magal, M. (2018). ACSM's guidelines for exercise testing and prescription. Philadelphia, US: Wolters Kluwer.

Rothman, KJ. (2008). BMI-related errors in the measurement of obesity. International Journal of Obesity, 32, S56-S59.

Shiely, F., Perry, I.J., Lutomski, J., Harrington, J., Kelleher, C.C., McGee, H. \& Hayes, K. (2010). Temporal trends in misclassification patterns of measured and self-report based body mass index categories-findings from three population surveys in Ireland. BMC Public Health, 10, 560.

Sobal, J. (1991). Obesity and socioeconomic status: A framework for examining relationships between physical and social variables. Medical Anthropology, 13, 231-247. 
Sörensen, L., Smolander, J., Louhevaara, V., Korhonen, O. \& Oja, P. (2000). Physical activity, fitness and body composition of Finnish police officers: a 15-year follow-up study. Occupational Medicine, 50, 3-10.

Steinhardt, M., Greenhow, L. \& Stewart, J. (1991). The relationship of physical activity and cardiovascular fitness to absenteeism and medical care claims among law enforcement officers. American Journal of Health Promotion, 5, 455-460.

Sullivan, G. M. \& Feinn, R. (2012). Using effect size-or why the P value is not enough. Journal of Graduate Medical Education, 4(3), 279-282.

Violanti, J.M., Ma, C.C., Fekedulegn, D., Andrew, M.E., Gu, J.K., Hartley, T.A., Charles, L.E. \& Burchfiel, C.M. (2017). Associations between body fat percentage and fitness among police officers: A statewide study. Safety and Health at Work, 8, 36-41.

Vuković, M., Kukić, F., Čvorović, A., Janković, D., Prćić, I. \& Dopsaj, M. (2020). Relations between frequency and volume of leisure-time physical activity and body composition in police officers. Research Quarterly for Exercise and Sport, 91, 47-54.

Wen, M. \& Kowaleski-Jones, L. (2012). Sex and ethnic differences in validity of self-reported adult height, weight and body mass index. Ethnicity \& Disease, 22, 72.

WHO. (2017). Obesity and overweight [WHO]. WHO. https://www.who.int/newsroom/fact-sheets/detail/obesity-and-overweight 